\title{
METACOGNITION AND RUMINATIVE THINKING AS PREDICTORS OF BURNOUT: A STRUCTURAL EQUATION MODELLING
}

\author{
Mahmut EVLI'1* ${ }^{*}$, Nuray ŞìMŞEK ${ }^{1}$ \\ ${ }^{1}$ Erciyes University, Faculty of Health Sciences, 38039, Melikgazi, Kayseri, Turkey
}

\begin{abstract}
Nursing education is a difficult process with both theoretical and clinical practice. This difficult process creates pressure and stress in nursing students. Therefore, students cannot notice emotions and thinking and may experience rumination. In this case, it can occur in burnout in addition to many mental illnesses. The aim of this study was to investigate whether metacognition and rumination had a predictive effect on burnout. The sample of the study consisted of 280 nursing students who volunteered to participate in the study, and it was completed with 261 nursing students who completed the measurement tools completely. Data were collected using an introductory information form, Ruminative Thinking Style Scale, Metacognitions Questionnaire 30, and Maslach Burnout Inventory. Correlation analysis and structural equation modeling were used to analyze the data. It was determined Ruminative Thinking averages of the participants was $87.61 \pm 2.59$, Total Metacognitions averages $73.96 \pm 11.80$, Emotional Exhaustion averages $24.63 \pm 5.55$, Depersonalization averages $9.58 \pm 2.79$, Personal average $28.54 \pm 5.34$. In this study, it is seen that high metacognitions and ruminative thinking styles of students affect burnout. But ruminative thinking has not a mediating role in the relationship between metacognitions and burnout.
\end{abstract}

Keywords: Metacognition, Ruminative thinking, Burnout, Structural equation modelling

*Corresponding author: Erciyes University, Faculty of Health Sciences, 38039, Melikgazi, Kayseri, Turkey

E mail: mahmutevli38@gmail.com (M. EVLi)

$\begin{array}{lll}\text { Mahmut EVLi } & \text { (iD) https://orcid.org/0000-0002-5113-7619 } & \text { Received: October 20, 2020 }\end{array}$

Nuray ȘiMȘEK (iD) https://orcid.org/0000-0003-2325-791X

Accepted: December 21, 2020

Published: May 01, 2021

Cite as: Evli M, Şimşek N. 2021. Metacognition and ruminative thinking as predictors of burnout: a structural equation modelling. BSJ Health Sci, 4(2): 6976.

\section{Introduction}

The changes in human life lead to many positive and negative changes on both his/her private and business life. The stress arising from these changes can be seen as a natural part of daily or business life. The fact that individuals do not have the chance to prove themselves and be supported in such an experiential atmosphere increases their stress and hence can lead to burnout (Çokluk, 2003).

Freudenberger (1977) used the concept of burnout for the first time and described burnout as people's exhaustion and failure because of their high expectation on their own energy and power resources. Maslach and Jackson (1981) defined burnout as individuals' emotional exhaustion because of the works they perform, and their negative attitude towards the changing environmental factors. Emotional exhaustion which is a significant aspect of burnout is individuals' failure to devote psychologically themselves, for a long time, to the works they perform, when their emotional resources are worn or run out. Another important aspect is that individuals develop negative and cynical emotions and behaviours towards the persons opposite them (customer, patient, teacher, student etc.). Considering burnout, these two aspects are inter-related. Maslach, who conducted major studies on burnout and developed inventory on it, divided the emotions associated with burnout into 3 aspects including emotional exhaustion, depersonalization and diminished personal accomplishment (Maslach and Jackson, 1981; Maslach et al., 2001). Emotional exhaustion is characterized by tiredness, fatigue, lack of self-confidence, libido loss and weakness. Depersonalization represents the interpersonal aspect of burnout characterized by callous, insincere and indifferent attitudes towards others and even improper response in inter-personal relations (Maslach et al., 2001). Assumed to emerge as a result of burnout, the aspect of diminished personal accomplishment is characterized by development of negative judgements, as a consequence of individuals' self-assessment, accompanied by inadequacy, low or lack of motivation to succeed, reduced professional efficiency and productivity, negative inter-personal relations, inability to overcome and resolve problems and decreased self-esteem (Maslach et al., 2001). Depending on these circumstances, a great number of physical, behavioral and psychological disorders may emerge (Ardıç and Polatçı, 2009). It was reported that the psychiatric disorders such as stress, anxiety and depression aggravate along with burnout (Creedy et al., 
2017). Rumination and metacognition are significant patterns to understand development of these negative emotional states that emerge (Smith and Alloy, 2009). It is known that rumination has adverse impact on burnout and positive correlation with it (Brackett et al., 2010; Luo and Zhao, 2013). Various theoretical definitions have been made with respect to rumination which is defined also as intellectual reflection. Some definition models suggest that rumination focuses on negative emotional states and/or those covering/surrounding this emotion whereas other models focus on inconsistency between the individual's current state and the desired status/state. Whatever the definition is, the most important focus here is the damage and uncontrollability in metacognitions in case of negative situations (Smith and Alloy, 2009).

This state that refers to thinking about thinking and emerges in metacognitions leads to many psychiatric disorders (Cotter et al., 2017). There are studies that demonstrate maladaptive metacognitions are effective in development of substance-use disorders/addictions (Wasmuth et al., 2015), eating disorders (Olstad et al., 2015), anxiety and depressive disorders (Nordahl et al., 2018), rage disorders (Simpson and Papageorgiou, 2003) and psychotic disorders (Morrison et al., 2007). In addition, it is seen that metacognitions and ruminative thinking are closely related with psychopathology and constitute a vicious circle in terms of mental disorders (Roelofs et al., 2007; Meyer et al., 2009). It can be assumed that this vicious circle may both deepen psychopathology and also expedite burnout.

Nonetheless, the literature review shows that studies focus on the relationship between metacognitions and rumination or psychiatric disorders (Meyer et al., 2009; Morrison et al., 2007; Olstad et al., 2015; Roelofs et al., 2007; Wasmuth et al., 2015), and that the studies on the relationship between rumination and burnout are limited (Boren, 2014; Vandevala et al., 2017), and that there is no study examining the interaction between these three concepts. Therefore, this study was shaped by the inquiry on to what extent metacognitions and rumination predict burnout especially before it develops. This study aimed to examine to what extent metacognitions and rumination accounts for burnout. During undergraduate education, nursing students both receive intensive theoretical training and practice the provision of healthcare. This process is a stressful experience for students (Da Silva et al., 2014). There are studies that reported that burnout level is high among nursing students who experience this challenging education process. It was thinking that it would be appropriate to examine the conceptual relationship related to burnout to prevent students' burnout. (Rudman and Gustavsson, 2012).

This study aimed to answer the question "Are metacognitions and rumination predictor of burnout?". So, the following hypotheses were tested:

$\mathrm{H}_{1}$ : Metacognitions affect the burnout level.
$\mathrm{H}_{2}$ : Metacognitions affect the ruminative thinking style. $\mathrm{H}_{3}$ : Ruminative thinking style affects the burnout level. $\mathrm{H}_{4}$ : Ruminative thinking style mediates between metacognitions and burnout.

To test the above hypotheses, the following hypothesis model has been created (Figure 1).

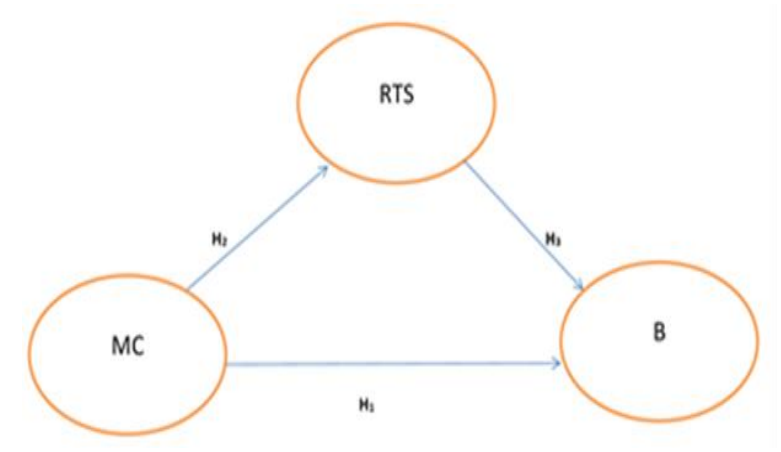

Figure 1. Variable Model in which hypotheses will be evaluated $(\mathrm{MC}=$ Metacognitions, $\mathrm{B}=$ Burnout level, $\mathrm{RTS}=$ Ruminative thinking style).

\section{Material and Methods}

\subsection{Study Design and Sample Size}

Cross-sectional design was used in this study. Structural equation modelling (SEM) was used in order to reveal the relationship between metacognitions and burnout and investigate deeply the effect of ruminative thinking on this assumed relationship. There is no clear consensus on the number of sample in structural equation modelling (Waltz et al., 2017). With the purpose of determining the minimum sample size in this study, the hypothesis testing framework was used as an indicator of statistical power for the root mean square error of approximation (RMSEA). RMSEA value which is 0.05 or below it is considered as good model fit, between 0.05-0.08 as adequate model fit, between $0.08-0.10$ as acceptable model fit and above 0.10 as unacceptable model fit (Kline, 2011). Also, the research sample was taken as 280 students in line with the literature recommendation taking into account that it shouldn't be less than 10 times the number of variables observed in the model and 200 participants (Kline, 2011).

\subsection{Participants}

Data were collected from 08 October 2019 and 12 January 2020 in a health sciences faculty in Turkey. The students that are aged 18 years and above and can speak and understand Turkish participated in the study. The students were informed about the aim of the study, and that information would be kept confidential and they could withdraw from the study any time. It took 10-15 min. to fill in all data, and the students filled in the questionnaires themselves. All participants were thanked for their participation in the study. The study was completed with 261 students because 19 students filled in the forms not fully.

It was found out that $88.1 \%$ of the participants are female; $46.0 \%$ of them live in cities; family monthly 
income of $51.0 \%$ of them is between 2,501 and $5,000 \mathrm{TRY}$; individual monthly expenditure of $49.8 \%$ of them amounts to 0-500TRY; mother's total year of education of $66.3 \%$ and father's total year of education of $47.9 \%$ of them is between 5 and $8 ; 94.3 \%$ of them have no psychiatric diagnosis or no information on their diagnosis and $90.4 \%$ of them didn't use any psychiatric medicine in the past.

\subsection{Instruments}

The socio-demographic characteristics consisted of the questions such as gender, age, academic success, family monthly income and individual monthly expenditure that are considered to be influential on dependent variables.

\subsection{Ruminative Thinking Style Scale}

Ruminative Thinking Style Scale, which was developed by Brinker and Dozois (2009) and aimed to assess an individual's general thinking style without taking into account his/her present emotional state, was used in this study. The 7-likert type scale consists of 20 items. The items are scored by giving a point between $7=$ very strongly agree and $1=$ very strongly disagree. The scale which does not have a cut point assesses the individuals' ruminative thinking tendencies (Brinker and Dozois, 2009).

The Turkish validity and reliability of the scale was performed by Karatepe et al. (2013), and its internal consistency coefficient was calculated as $r=0.907$, and the total score correlations of the items as between 0.474 and 0.699 , as well as its test-retest correlation coefficient as 0.84 . The scale was reported to be a reliable measurement instrument for assessment of ruminative thinking style (Karatepe et al., 2013). For this study, Cronbach alpha coefficient of the scale is 0.91 .

\subsection{Metacognitions Questionnaire-30}

The short version of the questionnaire that was developed by Wells and Cartwright (2004) in order to assess the various aspects of metacognitive activities interrelated with psychopathology. The 4-point Likerttype scale consists 30 questions. The questionnaire has five factors including positive beliefs about worry; negative beliefs about uncontrollability and danger of worry; cognitive confidence; need for controlling thinking and cognitive self-consciousness. Increasing scores mean high metacognitive activity psychopathologically (Wells and Cartwright, 2004).

The Turkish validity and reliability of the questionnaire was performed by Tosun and Irak (2008) and following the analysis to define the factor structure of questionnaire, it was determined that it has five-factor structure. It was expressed that these five factors accounted for $52.44 \%$ of the total variance and the factor structure of the Turkish version of Metacognitions Questionnaire-30 was at the same level with its original form. The scale consists of sub-dimensions the positive beliefs about worry, negative beliefs about uncontrollability and danger of worry, cognitive confidence, controlling thinking and cognitive selfconsciousness. Those who have high score in this factor tend to observe and examine their own thinking and thinking processes (Tosun and Irak, 2008).

Following the analyses on reliability of the questionnaire, it was found that its internal consistency Cronbach alpha coefficient is 0.93 , and Cronbach alpha values for subscales to range between 0.72 and 0.93 . Also test-retest correlation coefficients are between 0.40 and 0.94 for the questionnaire items and between 0.70 and 0.85 for the factors. Cronbach alpha reliability coefficient is 0.86 for the whole questionnaire (Tosun and Irak, 2008). In our study, Cronbach alpha coefficients are between 0.66 and 0.83 for the factors while it is 0.85 for the whole questionnaire.

\subsection{Maslach Burnout Inventory}

It was developed by Maslach and Jackson (1981) in order to determine individuals' burnout level. Consisting of 22 items, this five-Likert type scale (1-5) has three components including emotional exhaustion, depersonalization and personal accomplishment. The option "never" is scored 0 while the option "always" is scored 4. The scale consists of sub-dimensions the emotional exhaustion, depersonalization and personal accomplishment. The lowest and highest scores that can be obtained from the inventory are 0 and 36 respectively for the component of emotional exhaustion; 0 and 20 for depersonalization, and 0 and 32 for personal accomplishment. In the reliability study conducted by Ergin (1993) for the components, Cronbach Alpha coefficients were found as $0.82,0.60$, and 0.80 respectively. The components of the inventory are assessed separately and there is not a total inventory score. High score in the components of emotional exhaustion and depersonalization, and low score in the component of personal accomplishment indicate high burnout level. For this study, Cronbach alpha coefficient is 0.82 for emotional exhaustion, 0.77 for depersonalization and 0.66 for personal accomplishment.

\subsection{Statistical Analysis}

In order to accomplish blindness, the data of the study were evaluated by an external researcher who was not included in the study. IBM SPSS v25 was used for analysing the data collected in this study. Internal consistency of research instruments was tested by calculating Cronbach alpha coefficient, and factor analysis was used for assessing the structure validity. Scale internal consistency of Cronbach's alpha coefficients are given in the introductory part of the scale. Basic components technique was applied for explanatory factor analysis It was determined that for all scales was Kaiser-Meyer-Olkin (KMO) test value $>0.80$ and $\mathrm{P}<0.01$ for Barlett's test of sphericity. From these findings, it can be seen that it can be used safely without removing any item from the scales (Gürbüz ve Şahin, 2018). In the evaluation of the data, Shapiro-Wilk test was applied to evaluate the conformity to the normal distribution and the data were found to be normally distributed $(\mathrm{P}>0.05)$. Therefore Pearson correlation test was used for correlation. $\mathrm{P}<0.05$ was considered 
statistically significant.

LISREL 8.71 (Jöreskog and Sorbo 2004) program was implemented for structural equation modeling. Maximum Likelihood (ML) method was used in structural equation modelling. In order to test fitness of the model, the following indices were assessed: CMIN/DF < 5; Root Mean Square Error of Approximation (RMSEA) < 0.08; Goodness of Fit Index (GFI)> 0.90; Adjusted Goodness of Fit Index (AGFI) > 0.90; and Comparative Fit Index (CFI) $>0.90$ were applied (Çapık, 2014; Sun, 2005). For comparisons, $\mathrm{P}<0.05$ was considered statistically significant.

\subsection{Ethical Consideration}

For this study, the approval was obtained from the Social and Humanities Ethics Committee (Approval Date: 28.05.2019 / Approval Number: 71) and the permission of the institution was achieved from the Dean of the Faculty of Health Sciences. Also the informed voluntary consent form was received from the students who accepted to take part in the study.

\section{Results}

In our study, the findings of nursing students on correlation between scale score averages are indicated in Table 1. As a predictor and mediator model, the structural equation modelling between metacognitions, burnout and ruminative thinking is pointed in Figure 2 and Table 2, Table 3.

Table 1. Mean, standard deviation and correlation values of ruminative thinking style, metacognitions, burnout inventory and subscales $(\mathrm{n}=261)$

\begin{tabular}{|c|c|c|c|c|c|c|c|c|c|c|c|}
\hline Variables & $\mathrm{X}$ & SS & 1 & 2 & 3 & 4 & 5 & 6 & 7 & 8 & 9 \\
\hline 1. RTS & 87.61 & 2.59 & - & & & & & & & & \\
\hline 2. MC-POS & 13.95 & 3.56 & $.137^{*}$ & - & & & & & & & \\
\hline 3. MC-NEG & 14,61 & 3.47 & $.394^{* *}$ & $.137^{*}$ & - & & & & & & \\
\hline 4. MC-CC & 13.06 & 4.21 & $.228^{* *}$ & .097 & $.300 * *$ & - & & & & & \\
\hline 5. MC-NC & 15.05 & 3.86 & $.617^{* *}$ & .093 & $.499 * *$ & $.388^{* *}$ & - & & & & \\
\hline 6. MC-CSC & 17.27 & 3.00 & $.457^{* *}$ & $.254^{* *}$ & $.477^{* *}$ & $.177^{* *}$ & $.403^{* *}$ & - & & & \\
\hline 7. MC & 73.96 & 11.80 & $.557^{* *}$ & $.472^{* *}$ & $.727^{* *}$ & $.646^{* *}$ & $.743^{* *}$ & $.667^{* *}$ & - & & \\
\hline 8. EE & 24.63 & 5.55 & $.321^{* *}$ & .056 & $.233^{* *}$ & .080 & $.285^{* *}$ & .111 & $.236^{* *}$ & - & \\
\hline 9. D & 9.58 & 2.79 & $.306^{* *}$ & .083 & $.289 * *$ & $.183^{* *}$ & $274^{* *}$ & $.150^{*}$ & $.303^{* *}$ & $611^{* *}$ & - \\
\hline 10. PA & 28.54 & 5.34 & .-035 & 0.37 & -.110 & -.099 & -.112 & $.146^{*}$ & -.056 & -.046 & $-.153^{*}$ \\
\hline
\end{tabular}

$\mathrm{RT}=$ ruminative thinking style, $\mathrm{MC}$-POS= metacognitions-positive beliefs about worry, MC-NEG= metacognitions-negative beliefs about controllability and danger of worry, $\mathrm{MC}-\mathrm{CC}=$ metacognitions-cognitive confidence, $\mathrm{MC}-\mathrm{NC}=$ metacognitions-need for control, $\mathrm{MC}-\mathrm{CSC}=$ metacognitions-cognitive self-consciousness, $\mathrm{MC}=$ total Metacognitions, $\mathrm{EE}=$ emotional exhaustion, $\mathrm{D}=$ depersonalization, $\mathrm{PA}=$ personal accomplishment, ${ }^{*} \mathrm{P}<0.05,{ }^{* *} \mathrm{P}<0.01$.

In our study, the mean scores of the scale was found as follows: Ruminative Thinking Style (RTS) $=87.61 \pm 2.59$, Metacognitions-positive beliefs about worry (MCPOS) $=13.95 \pm 3.56$, Metacognitions negative beliefs about uncontrollability and danger of worry (MC$\mathrm{NEG})=14.61 \pm 3.47$, Metacognitions-cognitive confidence (MC-CC) $=13.06 \pm 4.21$, Metacognitions-need for control (MC-NC)=15.05 \pm 3.86 , Metacognitions-cognitive selfconsciousness (MC-CSC) $=17.27 \pm 3.00, \quad$ Total Metacognitions $\quad(\mathrm{MC})=73.96 \pm 11.80, \quad$ Emotional Exhaustion $\quad(\mathrm{EE})=24.63 \pm 5.55$, Depersonalization (D)=9.58 \pm 2.79 , and Personal Accomplishment $(\mathrm{PA})=28.54 \pm 5.34$ (Table 1$)$. It was discovered that there is a positive significant relationship statistically between RTS and MC and their factors $(\mathrm{P}<0.05 / \mathrm{P}<0.01$ ) (Table $1)$.

It was found out that RTS and MC have a positive and statistically significant relationship with EE and D (P < 0.01 ) whereas they have a negative and statistically insignificant relationship with PA $(\mathrm{P}>0.05)$ (Table 1). Regarding the factors of burnout, it was revealed that there is a positive and statistically significant relationship between $E E$ and $D(P<0.01)$ whereas there is a negative and statistically insignificant relationship between EE and PA ( $\mathrm{P}>0.05)$. It was determined that there is a negative and statistically significant relationship between $\mathrm{D}$ and $\mathrm{PA}(\mathrm{P}<0.05)$.

Examining the fit statistics of the structural equation modelling in Figure 2, the following values were discovered: $\mathrm{df}=326$ and $\mathrm{P}<0.05$. Although the model was considered as a fully-saturated model because of $\mathrm{df}>$ 0 , it was required to review the model fit indices due to $P$ $<0.05$. The fit indices of the model were determined as $\mathrm{CMIN} / \mathrm{DF}=1.712, \mathrm{GFI}=0.94, \mathrm{AGFI}=0.90, \mathrm{CFI}=0.95$, and $\mathrm{RMSEA}=0.052$. These values indicate that the data supports the model and the fit indices are acceptable (Çapık 2014; Sun 2005). 
Black Sea Journal of Health Science

Table 2. Regression weights, standardized regression weights and squared multiple correlations for model

\begin{tabular}{|c|c|c|c|c|c|c|c|}
\hline \multirow[b]{2}{*}{ Variables } & & & \multicolumn{2}{|c|}{ Estimate } & \multirow[b]{2}{*}{ S.E. } & \multirow[b]{2}{*}{$\mathrm{t}$} & \multirow[b]{2}{*}{$\mathrm{P}$} \\
\hline & & & Unstandardized $\beta$ & Standardized $\beta$ & & & \\
\hline RTS & $<---$ & MC & 0.528 & 0.797 & 0.077 & 6.863 & 0.001 \\
\hline B & $<---$ & $\mathrm{MC}$ & 0.659 & 0.247 & 0.418 & 1.576 & 0.115 \\
\hline \multirow[t]{2}{*}{ B } & $<---$ & RTS & 0.043 & 0.233 & 0.020 & 2.191 & 0.028 \\
\hline & & SMC & & & & & \\
\hline RTS & & & 0.636 & & & & \\
\hline B & & & 0.208 & & & & \\
\hline
\end{tabular}

$\mathrm{MC}=$ metacognitions, $\mathrm{B}=$ burnout level, $\mathrm{RTS}=$ ruminative though style, $\mathrm{S} . \mathrm{E} .=$ standard error, $\mathrm{SMC}=$ squared multiple correlations.



Figure 2. Structural equation modeling regarding metacognition, ruminative thinking style and burnout (MC= metacognitions, $\mathrm{B}=$ burnout level, RTS= ruminative thinking style, MC-POS= metacognitions-positive beliefs about worry, MC-NEG= metacognitions-negative beliefs about uncontrollability and danger of worry, MC-CC= metacognitionscognitive confidence, $\mathrm{MC}-\mathrm{NC}=$ metacognitions-need for control, $\mathrm{MC}-\mathrm{CSC}=$ metacognitions-cognitive self-consciousness, $\mathrm{EE}=$ emotional exhaustion, $\mathrm{D}=$ depersonalization, $\mathrm{PA}=$ personal accomplishment).

Examining the fit statistics of the structural equation modelling in Figure 2, the following values were discovered; $\mathrm{df}=326$ and $\mathrm{P}<0.05$. Although the model was considered as a fully-saturated model because of $\mathrm{df}>0$, it was required to review the model fit indices due to $\mathrm{P}<0.05$. The fit indices of the model were determined as $\mathrm{CMIN} / \mathrm{DF}=1.712, \mathrm{GFI}=0.94, \mathrm{AGFI}=0.90, \mathrm{CFI}=0.95$, and RMSEA $=0.052$. These values indicate that the data supports the model and the fit indices are acceptable (Çapık 2014; Sun 2005).

One-unit change in the metacognition level by the values in Table 2 leads to a unit change corresponding to 0.659 in the burnout level and this change is not statistically significant $(P>0.05)$. Likewise, one standard deviation change in the metacognition level causes a standard deviation corresponding to 0.24 in the burnout. Also, this model accounts for $63.6 \%$ of variance in ruminative thinking style and $20.8 \%$ variance in burnout level.

According to the results of diagram in Figure 2 and Table 2 , it is seen that the direct effect of metacognitions on the burnout level is $0.25(\mathrm{P}>0.05)$ and ruminative thinking style on the burnout level is $0.23(\mathrm{P}<0.05)$. Also, it is seen that the direct effect of metacognitions on the ruminative thinking style level is $0.80(\mathrm{P}<0.05)$. In the light of these findings, it can be suggested that the data fits the model and supports it. However, the change in path coefficient in the model shows not the mediator impact of ruminative thinking style in the relationship between metacognitions and burnout (Table 3). 
Black Sea Journal of Health Science

Table 3. Standardized estimates of direct and indirect effects on burnout

\begin{tabular}{|c|c|c|c|c|}
\hline \multirow[t]{2}{*}{ Impact Status } & & \multicolumn{2}{|c|}{$\begin{array}{l}\text { Bias-corrected 95\% Effect Value } \\
\text { (Lower/Upper) }\end{array}$} & \multirow{2}{*}{$\begin{array}{c}\text { Hypothesis } \\
\text { Acceptance } \\
\text { Status }\end{array}$} \\
\hline & & $\mathrm{MC}$ & RTS & \\
\hline \multirow{4}{*}{ Direct Effects } & RTS & $0.797(0.710 / 0.876)$ & - & \multirow{3}{*}{$\begin{array}{c}\mathrm{H}_{1}, \mathrm{H}_{2} \text { and } \mathrm{H}_{3} \\
\text { accept }\end{array}$} \\
\hline & $\mathrm{B}$ & $0.247(-0.103 / 0.584)$ & $0.233(-0.101 / 0.570)$ & \\
\hline & $\mathrm{P}$ & 0.001 & 0.022 & \\
\hline & RTS & - & - & \multirow{3}{*}{$\mathrm{H}_{4}$ reject } \\
\hline \multirow[t]{2}{*}{ Indirect Effects } & $\mathrm{B}$ & $0.179(-0.078 / 0.481)$ & - & \\
\hline & $\mathrm{P}$ & 0.134 & - & \\
\hline
\end{tabular}

$\overline{\mathrm{MC}}=$ metacognitions, $\mathrm{B}=$ burnout level, $\mathrm{RTS}=$ ruminative though style.

\section{Discussion}

The aim of this study is to reveal the effect of metacognitions and ruminative thinking style on burnout as well as the mediator impact of ruminative thinking style in the relationship between metacognitions and burnout, among nursing students, by establishing structural equation modelling. It was seen that metacognitions and ruminative thinking style affected the nursing students' burnout levels, and ruminative thinking style played not a mediator role in this interaction.

In our study, it was found out that there is a close relationship between metacognitions and burnout, and the changes in burnout level are under the influence of metacognitions (Table 1, Table2 and Figure 2). Therefore, $\mathrm{H} 1$ was accepted. It is knowns that nurses and nursing students have high burnout level (Da Silva et al., 2014; Da Silva et al., 2018; Zaghini et al., 2020). It can result from the fact that they take care of human directly and they are subject to academic demands such as tests, theoretical and practical training activities, research activities, and professional practices such as healthcare services and communication with patients as well as practices in provision of healthcare services (Da Silva et al., 2014). Such issues increase nursing students' stress and hence lead to psychological morbidity and burnout (Watson et al., 2008). Burnout causes a reduction in persons' ability to fulfil normal functions neuropsychologically and weakens their capability to cope with stressors. The metacognitive functions that are used as a continuous re-assessment method provide coordination and bridge between different areas of memory functions and they are also influential on focusing and directing attention (Iskander, 2019). Dysfunctional metacognitions and ineffective coping significantly affect individuals' working ability and capacity and hence lead to gathering of stressors (Lenzo et al., 2016). This situation is considered to cause a vicious circle between dysfunctional metacognitions, ineffective coping and burnout.

This study discovered that there is a relationship between ruminative thinking style and burnout, and that the changes in individuals' burnout levels are affected by ruminative thinking style (Table 1, Table 2 and Figure 2). Hence, H3 was accepted from the study hypotheses. A person suffering from emotional exhaustion, depersonalization and diminished personal accomplishment tend more to have negative selfassessment (Maslach et al., 2001). Rumination that is a passive way for individuals to cope with negative selfassessment (Lyubomirsky and Nolen-Hoeksema, 1993) generally leads to a long-term depressive mood and feeling of loss of control over one's own life (Carver and Scheier, 1990; Nolen-Hoeksema, 1991). The psychological and physiological arousal in rumination, which is classified on the basis of emotional arousal, is high and it is challenging cognitively and emotionally. Therefore, this situation has adverse effect on the wellbeing of people with ruminative thinking style (Cropley and Zijlstra, 2011). Accordingly, chronic fatigue and stress level increases and hence burnout may emerge (Maslach et al., 2001).

It is known that there is a significant relationship between metacognitive beliefs and rumination (Moulds et al., 2010). Our study discovered that there is a significant relationship between metacognitions and ruminative thinking, and that $64 \%$ of the changes in ruminative thinking level are under the influence of metacognitions (Table 2, Figure 2). Thus, H2 was accepted from the study hypotheses. Rumination which is an individual's insistent thinking over his/her emotions and problems without using active problemsolving skills (Nolen-Hoeksema et al., 2008) is a component of Cognitive Attentional Syndrome (CAS), and it was defined as repetitive thinkings about subjective experience during a final social interaction including selfassessment, external assessment of partners and other details of the event in the context of social concern (Kashdan and Roberts, 2007). According to SelfRegulatory Executive Function (S-REF) model which is used for explaining rumination process, it is required to focus on the mechanisms that produce, follow and maintain the challenging thinkings and experience rather that these thinkings and experience themselves (Wells, 2011). S-REF model highlights that psychological disorders result from an individual's inflexible and 
maladaptive reaction to events which is called as CAS. CAS involves constant worry and rumination, threat monitoring and ineffective coping strategies that contribute to continuation of problem (Wells, 2013).

Since the relationship between metacognition, rumination and burnout hasn't been addressed before, it is thinking that this study will provide a new contribution to the literature. According to the results of the model established (Figure 2), metacognitions affect ruminative thinkings. Excessive level of ruminative thinking increases individuals' burnout level. It is seen that ruminative thinking has not a mediator role in the relationship between metacognitions and burnout (Table 3 and Figure 2). Thus, H3 was not accepted. With the purpose of analysing the mechanisms which interrelate metacognition and burnout, it is assumed that more researches are needed to be conducted to investigate the relationship between these structures.

\subsection{Limitations and Strengths of Study}

It should be accepted that our study has some limitations. Since this study has a cross-sectional design, the results involve instant assessments. It is thinking that a longitudinal research will be a more suitable design for investigating, in terms of the established model, the relationships and causality over time. Also, although our research sample was considered adequate for analysing the established model, it is assumed that a larger sample will allow us to go beyond our existing analysis level for studying the differences of both dependent and independent variables (e.g. gender and age). The answers given by the participants to the data collection instruments, which were used for the dependent variables in the established model, were considered correct, but the answers given to the study are limited with the scale items. Strengths of the research are sufficient sample size and statistical method used.

\section{Conclusion}

According to the results of the study, the burnout levels of nursing students are affected by metacognitive activities and ruminative thinking style. Nursing education is both theoretical and applied education. Hence, it can be said that nursing students face many problems and, accordingly, focus on negative mood and / or situations involving this emotion. This situation can be said to increase the level of rumination in nursing students. Students who have low ability to thinking and realize their thinkings (metacognitions) experience more rumination. This situation drags students into a vicious circle and results in burnout. Nursing students, the future nursing professionals, needs to be improved to ability of recognize and express their feelings and thinkings. Thus, issues such as awareness and communication should be included both in the education curriculum and supported by private courses.

\section{Author Contributions}

ME, contributed conception, design, acquisition of data and analysis of the study, and to drafting and revising the article critically for important intellectual content. NŞ, contributed interpretation of data and revising the article critically, and final approval of the version to be submitted.

\section{Conflict of Interest}

The authors declare that there is no conflict of interest.

\section{Acknowledgements}

Thank you to all the volunteers who participated in the study. No support has been received from any person or institution for this study.

\section{References}

Ardıç K, Polatçı S. 2009. Burnout syndrome and the other sıde of medallıon: Engagement. J Erciyes Univ Inst Econ Admin Sci, 32: 21-46.

Boren JP. 2014. The relationships between co-rumination, social support, stress, and burnout among working adults. Manag Commun Quart, 28(1): 3-25. DOI: 10.1177/0893318913509283.

Brackett MA, Palomera R, Kaja-Mojsa J, Reyes MR, Salovey P. 2010. Emotıon-regulation ability, burnout, and job satisfaction among British secondary-school teachers. Psychology in the Schools, 47(4): 406-417. DOI: 10.1002/pits.20478.

Brinker JK, Dozois JA. 2009. Ruminative thinking style and depressed mood. J Clinical Psychol, 5(1): 1-19. DOI: 10.1002/jclp.20542.

Carver CS, Scheier MF. 1990. Origins and functions of positive and negative affect: A control-process view. Psychol Rev, 97: 19-35. DOI: 10.1037/0033-295X.97.1.19.

Cotter J, Yung AR, Carney R, Drake RJ. 2017. Metacognitive beliefs in the at-risk mental state: A systematic review and meta-analysis. Behav Res Ther, 90: 25-31. DOI: 10.1016/j.brat.2016.12.004.

Creedy DK, Sidebotham M, Gamble J, Pallant J, Fenwick J. 2017. Prevalence of burnout, depression, anxiety and stress in Australian midwives: A cross-sectional survey. BMC Preg Childbirth, 17(13): 2-8. DOI: 10.1186/s12884-016-1212-5.

Cropley M, Zijlstra FRH. 2011. Work and rumination. In: Langan-Fox J, Cooper C, editors. Handbook of stress in the occupations. Edward Elgar Publishing Inc, Northampton, UK. pp. 487-501.

Çapık C. 2014. Use of confirmatory factor analysis in validity and reliability studies. Anatolian J Nursing Health Sci, 17(3): 196-205.

Çokluk Ö. 2003. Burnout in organizations. In: . Elma C, Demir K, editors. Contemporary approaches in management. Ani Publishing, Ankara, Turkey, pp. 109-134

Da Silva RM, Goulart CT, Lopes LF, Serrano PM, Costa AL, de Azevedo Guido L. 2014. Hardy personality and burnout syndrome among nursing students in three Brazilian Universities - analytic study. BMC Nurs, 13(1): 9. DOI: 10.1186/1472-6955-13-9.

Da Silva RM, Lopes LFD, Beck CLC, Grazziano ES, Costa ALS, Lopes VC. 2018. Demographic and academic characteristics that contribute to burnout occurrence in nursing students Analytic study. J Nursing Educ Pract, 8(8): 28-33. DOI: 10.5430/jnep.v8n8p28.

Ergin C. 1993. Burnout and adaptation of maslach burnout scale in doctors and nurses. In: Proceedings of VII. National 
Psychology Congress Scientific Studies, Turkish Psychological Association Publication, Hacettepe University, September 22-25, Ankara.

Freudenberger HJ. 1977. Burn-Out: Occupational hazard of the child care worker. Child Care Quart, 6(2): 90-99.

IBM SPSS Statistics. 2017. Sürüm 25.0. Armonk, NY: IBM Corp.

Iskander M. 2019. Burnout, Cognitive Overload, and Metacognition in Medicine. Med Sci Educ, 29(1): 325-328. DOI: $10.1007 / \mathrm{s} 40670-018-00654-5$.

Jöreskog K, Sörbom D. 2004. LISREL 8.71 (October 2004) Scientific Software International, Inc. Copyright.

Karatepe HT, Yavuz FK, Turkcan A. 2013. Validity and reliability of the Turkish version of the Ruminative Thinking Style Questionnaire. Bull Clinical Psychopharm, 23(3): 231-241. DOI: $10.5455 /$ bcp.20121130122311.

Kashdan TB, Roberts JE. 2007. Social anxiety, depressive symptoms, and post-event rumination: affective consequences and social contextual influences. J Anxiety Disord, 21(3): 284-301. DOI: 10.1016/j.janxdis.2006.05.009.

Kline BR. 2011. Principles and practice of structural modeling. The Guilford Press, New York-London, UK. 3rd ed., pp. 534.

Lenzo V, Indelicato F, Grisolia E, Toffle ME, Quattropani MC. 2016. The burnout syndrome in palliative home care workers: The role of coping strategies and metacognitive beliefs. Medit J Clin Psychology, 4(1): 1-12. DOI: 10.6092/2282-1619/2016.4.1120.

Luo P, Zhao B. 2013. Affectivity, emotional exhaustion, and service sabotage behavior: The mediation role of rumination. Social Behav Person, 41(4): 651-662. DOI: 10.2224/sbp.2013.41.4.651.

Lyubomirsky S, Nolen-Hoeksema S. 1993. Self-perpetuating properties of dysphoric rumination. J Person Soc Psych, 65(2): 339-349. DOI: 10.1037//0022-3514.65.2.339.

Maslach C, Jackson SE. 1981. The measurement of experienced burnout. J Occup Behav, 2: 99-113.

Maslach C, Schaufeli WB, Leiter MP. 2001. Job burnout. Annual Rev Psych, 52: 397-422.

Meyer RJ, Beck B, Riede K. 2009. Relationships between rumination, worry, intolerance of uncertainty and metacognitive beliefs. Person Indiv Differences, 46: 547-551. DOI: $10.1016 /$ j.paid.2008.12.010.

Morrison AP, French P, Wells A. 2007. Metacognitive beliefs across the continuum of psychosis: comparisons between patients with psychotic disorders, patients at ultra-high risk and non-patients. Behav Res Ther, 45(9): 2241-246. DOI: 10.1016/j.brat.2007.01.002.

Moulds ML, Yap CS, Kerr E, Williams, AD, Kandris E. 2010. Metacognitive beliefs increase vulnerability to rumination. Appl Cogn Psychol, 24: 351-364. DOI: 10.1002/acp.1681.

Nolen-Hoeksema S. 1991. Responses to depression and their effects on the duration of depressive episodes. J Abnormal Psych, 100(4): 569-582. DOI: 10.1037//0021843x.100.4.569.

Nolen-Hoeksema S, Wisco BE, Lyubomirsky S. 2008. Rethinking rumination. Perspect Psychol Sci, 3(5): 400-424. DOI: 10.1111/j.1745-6924.2008.00088.x.

Nordahl H, Nordahl HM, Vogel PA, Wells A. 2018. Explaining depression symptoms in patients with social anxiety disorder: Do maladaptive metacognitive beliefs play a role? Clin Psychol Psychother, 25(3): 457-464. DOI: 10.1002/cpp.2181.

Olstad S, Solem S, Hjemdal O, Hagen R. 2015. Metacognition in eating disorders: Comparison of women with eating disorders, self-reported history of eating disorders or psychiatric problems, and healthy controls. Eating Behav, 16: 17-22. DOI: 10.1016/j.eatbeh.2014.10.019.

Preacher KJ, Coffman DL. 2006. Computing power and minimum sample size for RMSEA. URL: http://quantpsy.org/rmsea/rmsea.htm (access date: 18.11.2019).

Roelofs J, Papageorgiou C, Gerber RD, Huibers M, Peeters F, Arntz A. 2007. On the links between self-discrepancies, rumination, metacognitions, and symptoms of depression in undergraduates. Behav Res Ther, 45(6): 1295-305. DOI: 10.1016/j.brat.2006.10.005.

Rudman A, Gustavsson JP. 2012. Burnout during nursing education predicts lower occupational preparedness and future clinical performance: A longitudinal study. Int J Nursing Stud, 49(8): 988-1001. DOI: 10.1016/j.ijnurstu.2012.03.010.

Simpson C, Papageorgiou C. 2003. Metacognitive Beliefs about rumination in anger. Cogn Behav Pract, 10: 91-94. DOI: 10.1016/S1077-7229(03)80012-3.

Smith JM, Alloy LB. 2009. A roadmap to rumination: A review of the definition, assessment, and conceptualization of this multifaceted construct. Clin Psych Rev, 29: 116-128. DOI: 10.1016/j.cpr.2008.10.003.

Sun J. 2005. Assessing goodness of fit in confirmatory factor analysis. Measur Eval Counseling and Deuelopmeni, 37: 240256.

Vandevala T, Pavey L, Chelidoni O, Chang NF, Creagh-Brown B, Cox A. 2017. Psychological rumination and recovery from work in intensive care professionals: associations with stress, burnout, depression and health. J Inten Care, 5(16): 2-8. DOI: 10.1186/s40560-017-0209-0.

Waltz CF, Strickland OL, Lenz ER. 2017. Measurement in nursing and health research. Springer Publishing Company, New York, USA, fifth edition, pp. 632.

Wasmuth SL, Outcalt J, Buck K, Leonhardt BL, Vohs J, Lysaker PH. 2015. Metacognition in persons with substance abuse: Findings and implications for occupational therapists. Can J Occup Ther, 82(3): 150-159. DOI: 10.1177/0008417414564865.

Watson R, Deary I, Thompson D, Li G. 2008. A study of stress and burnout in nursing students in Hong Kong: A questionnaire survey. Int J Nurs Stud, 45: 1534-542. DOI: 10.1016/j.ijnurstu.2007.11.003.

Wells A, Cartwright-Hatton S. 2004. A short form of the metacognitions questionnaire: Properties of the MCQ-30. Behav Res Therapy, 42: 385-396. DOI: 10.1016/S00057967(03)00147-5.

Wells A. 2011. Metacognitive therapy for anxiety and depression. Guilford Press, New York, USA, first edition pp. 316.

Wells A. 2013. Advances in metacognitive therapy. Int J Cognitive Ther, 6 (2): 186-201. DOI: 10.1521/ijct.2013.6.2.186.

Zaghini F, Biagioli V, Proiettic M, Badolamenti S, Fiorini J, Sili A. 2020. The role of occupational stress in the association between emotional labor and burnout in nurses: A crosssectional study. App Nursing Res, 151277. DOI: 10.1016/j.apnr.2020.151277. 